\title{
EFFICACY OF INSECTICIDES FOR LONGTAILED MEALYBUG CONTROL
}

\author{
N.A. MARTIN and P.J. WORKMAN \\ New Zealand Institute for Crop \& Food Research Limited, \\ Private Bag 92 169, Auckland
}

\begin{abstract}
Five insecticides, acephate ( $780 \mathrm{mg} /$ litre), imidacloprid $(50,100$ or $150 \mathrm{mg} / \mathrm{litre})$ and three experimental "organic" insecticides, YR55 (1.2 $\mathrm{g} /$ litre), YR65 (1 ml/litre) and YR70 (3.6 g/litre) as well as water control were applied three times (7-12 days apart) to pot plants of Asplenium bulbiferum (hen and chicken fern) infested with longtailed mealybugs (Pseudococcus longispinus). After three applications, the water-treated plants had $82 \%$ of fronds infested and a mean of 37 mealybugs on the youngest infested frond. The industry standard insecticide, acephate, reduced the mealybug populations to zero, while YR65 and imidacloprid reduced the infestation to $1-4 \%$ fronds infested and mean of $0.5-2.5$ mealybugs on the youngest infested frond. In these treatments only old fronds were infested. YR55 and YR70 gave poor control and young fronds were infested.
\end{abstract}

Keywords: Longtailed mealybug, juvenile stages, insecticide efficacy, Pseudococcidae.

\section{INTRODUCTION}

Mealybugs are a serious pest of many home and garden plants. The white waxy insects and the associated sooty mould spoil the appearance of plants. These pests are difficult to control with a single insecticide application, because some mealybugs are concealed and not hit by contact sprays and concealed females often cease to feed when egg laying starts. These non-feeding females cannot be killed with systemic insecticides. Once adult mealybugs establish on plants, the plants can be invaded by crawlers (first instar nymphs) over many weeks. One strategy to control the pest is to prevent the establishment of young mealybugs, by applying insecticides several times until crawler production ceases. A greenhouse experiment was undertaken to test the efficacy of a new strategy of applying a cluster of three sprays of insecticides to reduce severe mealybug infestations when all life stages were present. The trial also examined the efficacy of new insecticides for use on ornamental plants in the home and garden. These insecticides, including three "organic" products and imidacloprid, were compared with an industry standard, acephate. Imidacloprid is a systemic insecticide with good activity against sucking insects (Anon. 1992) and it does not have the smell associated with commercial formulations of acephate.

\section{MATERIALS AND METHODS}

Asplenium bulbiferum (hen and chicken fern) plants were grown one per $100 \mathrm{~mm}$ pot in a heated greenhouse. The plants were about $400 \mathrm{~mm}$ diameter when used.

Longtailed mealybug (Pseudococcus longispinus (Targioni-Tozzetti), (Hemiptera: Pseudococcidae) from a cycad were released onto the plants twice (18 May and 1 June 1998). Adult voucher specimens of the insects used have been deposited in the National Arthropod Collection, Mount Albert Research Centre, Auckland.

Prior to the first spray, plants were graded for severity of infestation then allocated to replicates (10) and treatments (8) (Table 1). Replicate one had the highest infestation and replicate 10 the lowest, which resulted in a gradation of infestation levels. The insecticides were applied on 15 and 27 July and 3 August 1998. The plants 
were individually sprayed to run off with a hand pumped Cambrian sprayer of the kind used by home gardeners. When the plants were dry they were returned to the greenhouse and each pot stood in one of ten metal trays, one tray per replicate. Each tray contained eight plants arranged randomly, one per treatment, with plants of similar initial infestation level in each tray. The treated plants were kept in a heated greenhouse.

During the experiment the plants continued to grow new fronds. These young fronds were the favoured sites for colonisation by the young mealybug, though the egg laying females probably stayed on old fronds.

Between 5 and 12 August mealybug infestation was assessed. The youngest frond infested with mealybug was selected from each plant and the numbers of live mealybugs of each life stage were recorded. The total number of fronds and number of infested fronds were also recorded. Phytotoxicity was assessed after the final spray. Data analysis

The total number of fronds and the total number of mealybug per frond after treatment were examined using log-linear modelling. The percent of fronds infested was examined using logistic regression (McCullagh and Nelder 1989). In each case, treatment differences were assessed after adjusting for any replicate differences. The method used to test for treatment effects was analogous to analysis of variance for an equivalent randomised block experiment. A similar analysis of each mealybug life stage was also conducted.

The mean numbers or percentages of mealybug infested fronds were predicted from the analyses for each treatment and adjusted for replicate differences. Results are presented along with $95 \%$ confidence intervals, which indicate the reliability of the predictions. All analyses were carried out using Genstat 5 release 4.1 (Genstat Committee 1998).

\section{RESULTS}

The total number of fern fronds per pot did not differ $(\mathrm{P}>0.05)$ between treatments, but the percentage of fronds infested with mealybug was different $(\mathrm{P}<0.001)$ for the different treatments (Table 1). All insecticide treated plants had fewer infested fronds than the water-treated plants $(\mathrm{P}>0.05)$.

TABLE 1: Mean number of fern fronds, percentage of fronds infested with mealybug and mean number of live mealybugs on youngest infested fronds on plants treated with different insecticides $(95 \%$ confidence limits in parentheses, $\mathrm{df}=63$ ).

\begin{tabular}{lccc} 
Treatment & $\begin{array}{c}\text { Mean number of } \\
\text { fronds per plant }\end{array}$ & $\begin{array}{c}\text { Percentage of } \\
\text { fronds infested }\end{array}$ & $\begin{array}{c}\text { Live mealybugs } \\
\text { on the youngest } \\
\text { infested frond }\end{array}$ \\
\hline Water control & $19(17,22)$ & $82(74,89)$ & $37(28,49)$ \\
Imidacloprid $^{1} 50 \mathrm{mg} / \mathrm{litre}$ & $19(17,22)$ & $6.3(3.1,12)$ & $2.5(0.9,6.9)$ \\
Imidacloprid $^{1} 100 \mathrm{mg} / \mathrm{litre}$ & $20(17,23)$ & $2.9(1.2,6.8)$ & $1.0(0.2,5.1)$ \\
Imidacloprid $^{1} 150 \mathrm{mg} / \mathrm{litre}$ & $20(18,23)$ & $1.0(0.2,4.5)$ & $0.5(0.0,5.0)$ \\
Acephate $^{2} 780 \mathrm{mg} /$ /litre & $20(17,23)$ & $0.0(0.0,2.4)$ & $0.0(0.0,0.8)$ \\
YR55 $1.2 \mathrm{~g} /$ litre & $18(16,21)$ & $59(49,68)$ & $26(19,36)$ \\
YR70 3.6 ml/litre & $23(20,26)$ & $28(21,38)$ & $16(11,24)$ \\
YR65 $1 \mathrm{ml} /$ litre & $20(18,23)$ & $3.7(1.6,8.5)$ & $1.1(0.2,5.2)$ \\
\hline
\end{tabular}

${ }^{1}$ As Confidor (50 g imidacloprid/kg)

${ }^{2}$ As Orthene (195 g acephate/litre)

Most of the mealybugs on the youngest fronds were first instar nymphs. Because there were few mealybugs on the more effective treatments, the data were combined for analysis. All insecticides reduced $(\mathrm{P}<0.001)$ the mean numbers of mealybugs on 
the youngest infested frond (Table 1). When plants had few mealybugs, they were restricted to older fronds, while the youngest fronds were infested on plants with high pest populations. Acephate treated plants had fewer mealybugs than plants from all other treatments. Mealybug numbers decreased with increasing concentration of imidacloprid, though this trend was not statistically significant. The mean numbers of mealybugs on YR65-treated plants were similar to those on imidacloprid-treated plants. The mean numbers of mealybug on the youngest infested frond were higher $(\mathrm{P}>0.05)$ on plants treated with YR70, YR55 and water than on all other plants, while the mean numbers of mealybugs on the youngest infested frond of plants treated with YR70 were lower $(\mathrm{P}>0.05)$ than on water-treated plants.

Only acephate showed signs of phytotoxicity, causing browning on the edges of both young and old fronds.

\section{DISCUSSION}

The industry standard insecticide, acephate, gave very good control of mealybug when applied as three sprays 7-12 days apart. However, it was the only treatment that was phytotoxic to fern plants. Imidacloprid and YR65 also gave good control of mealybug. In the effective treatments, only a few older fronds were infested, whereas plants treated with less effective insecticides had high proportions of fronds infested and these included the youngest fronds, indicating that continual colonisation was occurring.

A. bulbiferum was a good host for the longtailed mealybug and in the greenhouse continually grew new fronds which were colonised by young longtailed mealybugs. This host/pest combination is very suitable for testing the efficacy of insecticide for control of mealybugs.

The trial demonstrated the efficacy of using three applications of an insecticide to control a severe mealybug infestation. However, more information about the efficacy of each pesticide and the persistence of its activity would have been obtained from assessing the effects of a single application.

\section{ACKNOWLEDGEMENTS}

Ruth Butler (Crop \& Food Research) for statistical analysis and constructive comments; Madhu Madhusudhan and Tatyana Balint for technical assistance. Yates NZ Ltd funded this trial.

\section{REFERENCES}

Anon, 1992. Confidor: technical information. Bayer, Leverkusen, Germany 28 pp. Genstat Committee, 1998. Genstat 5 Release 4.1 Reference Manual Supplement. NaG, Oxford, UK. 229 pp

McCullagh, P. and Nelder, J.A., 1989. Generalised Linear Models (2nd edition). Chapman and Hall, London. 